\section{A) Check for updates}

Cite this: Dalton Trans., 2018, 47, 2406

Received 18th November 2017, Accepted 15th December 2017

DOI: $10.1039 / \mathrm{c} 7 \mathrm{dt} 04352 \mathrm{j}$

rsc.li/dalton

\title{
Synthesis and properties of $\mathrm{MoCl}_{4}$ complexes with thio- and seleno-ethers and their use for chemical vapour deposition of $\mathrm{MoSe}_{2}$ and $\mathrm{MoS}_{2}$ films $\dagger$
}

\author{
Yao-Pang Chang, Andrew L. Hector, (D) William Levason, (D) Gillian Reid (D) * and \\ Joshua Whittam
}

\begin{abstract}
Treatment of trans- $\left[\mathrm{MoCl}_{4}(\mathrm{MeCN})_{2}\right]$ with $\mathrm{L}\left(\mathrm{L}=\mathrm{Me}_{2} \mathrm{~S}, \mathrm{Me}_{2} \mathrm{Se}, \mathrm{THT}, \frac{1}{2} \mathrm{MeSCH}_{2} \mathrm{CH}_{2} \mathrm{SMe}\right)$ in $\mathrm{CH}_{2} \mathrm{Cl}_{2}$ solution, or reaction of $\mathrm{MoCl}_{5}$ with excess $L^{\prime}\left(L^{\prime}={ }^{n} \mathrm{Bu}_{2} \mathrm{~S},{ }^{n} \mathrm{Bu}_{2} \mathrm{Se}, \frac{1}{2} \mathrm{MeSCH}_{2} \mathrm{CH}_{2} \mathrm{SMe}, \frac{1}{2} \mathrm{PrSCH}_{2} \mathrm{CH}_{2} \mathrm{~S} \mathrm{Pr}^{\mathrm{P}}\right.$, $\frac{1}{2} \mathrm{MeSCH}_{2} \mathrm{CH}_{2} \mathrm{CH}_{2} \mathrm{SMe}, \frac{1}{2} \mathrm{MeSeCH}_{2} \mathrm{CH}_{2} \mathrm{CH}_{2} \mathrm{SeMe}$ ) in $\mathrm{MeCN}$, produces the Mo(Iv) complexes, [ $\left.\mathrm{MoCl}_{4}(\mathrm{~L})_{2}\right]$ and $\left[\mathrm{MoCl}_{4}\left(\mathrm{~L}^{\prime}\right)_{2}\right]$, respectively, in good yield. The new complexes have been characterised by IR and UVvis spectroscopy, elemental analysis and magnetic measurements, whilst crystal structure analyses of

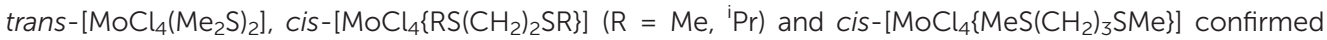
their identities and distorted octahedral geometries. The potential of $\left[\mathrm{MoCl}_{4}\left({ }^{n} \mathrm{Bu}_{2} \mathrm{E}\right)_{2}\right](\mathrm{E}=\mathrm{S}$, Se) as the first examples of molybdenum halide derived single source CVD precursors for the growth of $\mathrm{MoE}_{2}$ thin films was first probed by TGA, which showed multi-step decomposition processes, with the masses of the final residues consistent with $\mathrm{MoSe}_{2}(E=\mathrm{Se})$ and $\mathrm{MoCl}_{4}(E=S)$, respectively. Low pressure CVD experiments conducted at $750^{\circ} \mathrm{C}(\mathrm{E}=\mathrm{S})$ and $525^{\circ} \mathrm{C}(\mathrm{E}=\mathrm{Se})$ gave silvery and golden yellow films, respectively. Grazing incidence and in plane XRD data confirmed these to be $2 \mathrm{H}-\mathrm{MoE}_{2}$, whilst the texture of the $\mathrm{MoSe}_{2}$ was investigated using pole figure measurements. SEM and EDX data, optical and Raman data on the films are also reported.
\end{abstract}

\section{Introduction}

The coordination chemistry of molybdenum extends over nine formal oxidation states ( $-\mathrm{II}$ to $+\mathrm{VI})$ and has been intensively studied over the last 50 years. ${ }^{1-3}$ Over this period, in addition to exploring the basic chemistry, much effort has been devoted to studying the binding and reduction of dinitrogen by molybdenum complexes, ${ }^{2,4}$ and in modelling the active sites of molybdoenzymes. ${ }^{4,5}$ In the last 10 years the study of early d-block dichalcogenides, including $\mathrm{MoS}_{2}$ and $\mathrm{MoSe}_{2}$, has become the focus of much effort. Layered early transition metal dichalcogenides, $\mathrm{ME}_{2}(\mathrm{M}=\mathrm{Nb}, \mathrm{Ta}, \mathrm{V}, \mathrm{W}$, etc.; $\mathrm{E}=\mathrm{S}$, Se or $\mathrm{Te}$ ), are inorganic analogues of graphene, and their properties can be tuned by varying the metal and the chalcogen. Production of the materials as thin films maximises the anisotropy of their magnetic or electronic properties and thus methods to deposit 2D layers are of particular interest currently. ${ }^{6-8}$ Applications of these materials in optoelectronics, spintronics, sensors, electrocatalysts and magnetic materials

Chemistry, University of Southampton, Southampton SO17 1BJ, UK. E-mail: G.Reid@soton.ac.uk

$\dagger$ Electronic supplementary information (ESI) available. CCDC 1557208-1557213. For ESI and crystallographic data in CIF or other electronic format see DOI: $10.1039 / \mathrm{c} 7 \mathrm{dt} 04352 \mathrm{j}$ are being actively developed. ${ }^{8,9}$ The most common methods of forming $\mathrm{MoS}_{2}$ or $\mathrm{MoSe}_{2}$ thin films have been exfoliation from bulk samples, or heating $\mathrm{MoO}_{3}$ (or sometimes molybdenum metal) with $\mathrm{S}$ or Se in a hydrogen/inert gas atmosphere, to form the desired $\mathrm{MoE}_{2}(\mathrm{E}=\mathrm{S}$ or Se) 2D films on an appropriate substrate. ${ }^{10,11-13}$ Thermal decomposition of $\left[\mathrm{NH}_{4}\right]_{2}\left[\mathrm{MoS}_{4}\right]$ in a hydrogen atmosphere has also recently been reported. ${ }^{13}$

Chalcogenoether complexes of the early d-block metal halides can function as single source CVD precursors for some $\mathrm{ME}_{2}$ (for example, $\mathrm{M}=\mathrm{Ti}, \mathrm{V}$ or $\mathrm{Nb} ; \mathrm{E}=\mathrm{S}$ or Se). ${ }^{14,15}$ Chemical vapour deposition from molybdenum halide complexes has rarely been used to form molybdenum dichalcogenides, although $\mathrm{MoSe}_{2}$ films were produced by dual source atmospheric pressure chemical vapour deposition (CVD) using $\mathrm{MoCl}_{5}$ and either $\mathrm{Et}_{2} \mathrm{Se}$ or ${ }^{n} \mathrm{Bu}_{2} \mathrm{Se}^{16}{ }^{16}$ The tetrathiolate complex, $\left[\mathrm{Mo}\left(\mathrm{S}^{t} \mathrm{Bu}\right)_{4}\right]$, has also been used to deposit $\mathrm{MoS}_{2}$ films by CVD. ${ }^{17}$

Although there are a few early reports of $\mathrm{MoCl}_{4}$ complexes with mono-, di- and poly-thioethers and thiamacrocycles, ${ }^{1,2,18}$ the only recent work is the detailed characterisation, including the X-ray crystal structures, of trans- $\left[\mathrm{MoCl}_{4}\left(\mathrm{Et}_{2} \mathrm{~S}\right)_{2}\right]^{19}$ and trans$\left[\mathrm{MoCl}_{4}(\mathrm{THT})_{2}\right](\mathrm{THT}=$ tetrahydrothiophene $) .{ }^{20}$

Here we report the preparation, spectroscopic and structural characterisation of a series of new complexes of molybdenum(Iv) chloride with thio- and seleno-ether ligands and the evaluation of a subset of these as single source low pressure 
CVD reagents for the deposition of the corresponding $\mathrm{MoE}_{2}$ thin films.

\section{Experimental}

Syntheses were performed by using standard Schlenk and glove-box techniques under a dry $\mathrm{N}_{2}$ atmosphere. $\mathrm{MoCl}_{5}$ was obtained from Sigma-Aldrich and stored in a glovebox. Tetrahydrothiophene, $\mathrm{Me}_{2} \mathrm{~S}$ and ${ }^{n} \mathrm{Bu}_{2} \mathrm{~S}$ were purchased from Sigma-Aldrich and $\mathrm{Me}_{2} \mathrm{Se}$ from Strem. Solvents were dried by distillation from $\mathrm{CaH}_{2}\left(\mathrm{CH}_{2} \mathrm{Cl}_{2}, \mathrm{MeCN}\right), \mathrm{Na}\left(\mathrm{Et}_{2} \mathrm{O}\right)$ or $\mathrm{Na} /$ benzophenone ketyl (n-hexane). Dichalcogenoethers $\mathrm{MeE}\left(\mathrm{CH}_{2}\right)_{n} \mathrm{EMe}$ $(\mathrm{E}=\mathrm{S}$, Se; $n=2,3),{ }^{\mathrm{i}} \operatorname{PrS}\left(\mathrm{CH}_{2}\right)_{2} \mathrm{~S}{ }^{\mathrm{i}} \operatorname{Pr}$ and ${ }^{n} \mathrm{Bu}_{2} \mathrm{Se}$ were prepared via literature methods. ${ }^{21,22}$

Infrared spectra were recorded using a PerkinElmer Spectrum 100 spectrometer in the range $4000-200 \mathrm{~cm}^{-1}$, and samples prepared as Nujol mulls between CsI plates. UV/ visible spectra were recorded as powdered solids, using the diffuse reflectance attachment of a PerkinElmer 750S spectrometer. Microanalyses on new compounds were undertaken by London Metropolitan University. Thermogravimetric analysis (TGA) used a Netzsch TG209 F1 Libra analyser under a flow of argon at $65 \mathrm{~mL} \mathrm{~min}{ }^{-1}$, contained within a dry, nitrogen purged glovebox. The temperature was increased at a rate of $10{ }^{\circ} \mathrm{C} \min ^{-1}$.

\section{Single crystal X-ray experimental}

Data collections used a Rigaku AFC12 goniometer equipped with an enhanced sensitivity (HG) Saturn724+ detector mounted at the window of an FR-E+ SuperBright molybdenum $(\lambda=0.71073)$ rotating anode generator with VHF Varimax optics (70 micron focus) with the crystal held at $100 \mathrm{~K}$ ( $\mathrm{N}_{2}$ cryostream). Structure solution and refinement were performed using SHELX(S/L)97 and SHELX-2014/7 and were straightforward. ${ }^{23-25} \mathrm{H}$ atoms were added and refined using a riding model. The X-ray data collection details are in Table S1 (ESI $\dagger$ ). CCDC reference numbers in CIF format are $\left[\mathrm{MoCl}_{4}(\mathrm{NCMe})_{2}\right] \quad 1557208 ; \quad\left[\mathrm{MoCl}_{4}\left(\mathrm{Me}_{2} \mathrm{~S}\right)_{2}\right] \quad 557209 ; \quad\left[\mathrm{MoCl}_{4}\right.$ $\left.\left(\mathrm{MeSCH}_{2} \mathrm{CH}_{2} \mathrm{SMe}\right)\right]$ 557210; [ $\left.\left.\mathrm{MoCl}_{4}{ }^{\mathrm{i}} \mathrm{PrSCH}_{2} \mathrm{CH}_{2} \mathrm{~S}^{\mathrm{i}} \mathrm{Pr}\right)\right]$ 1557211; $\left[\mathrm{MoCl}_{4}\left(\mathrm{MeSCH}_{2} \mathrm{CH}_{2} \mathrm{CH}_{2} \mathrm{SMe}\right)\right]$ 1557212; $\left[\mathrm{MoCl}_{5}\left(\mathrm{Me}_{2} \mathrm{~S}\right)\right]\left[\mathrm{Me}_{2} \mathrm{~S}\right.$ $\left.\mathrm{CH}_{2} \mathrm{SMe}\right]$ 1557213. $\dagger$

\section{Complex synthesis}

trans $\left[\mathbf{M o C l}_{4}(\mathbf{M e C N})_{2}\right]$. Was made by a modified literature method. ${ }^{26} \mathrm{MoCl}_{5}(270 \mathrm{mg}, 1.0 \mathrm{mmol}$ ) was dissolved in MeCN $(20 \mathrm{~mL})$ with stirring for $30 \mathrm{~min}$ to give a dark brown solution. The solution was evaporated in vacuo. The resulting dark brown solid was washed by $n$-hexane $(5 \mathrm{~mL})$, the washings decanted off, and the solid dried in vacuo. Yield: $249 \mathrm{mg}, 78 \%$. Required for $\mathrm{C}_{4} \mathrm{H}_{6} \mathrm{Cl}_{4} \mathrm{MoN}_{2}$ (319.56): C, 15.02; $\mathrm{H}, 1.89 ; \mathrm{N}, 8.76$. Found: C, 14.84; H, 1.81; N, 8.61\%. IR ( $\left.\mathrm{Nujol} / \mathrm{cm}^{-1}\right)$ : 2314, 2283 (MeCN), 335 (Mo-Cl).

trans-[ $\left.\mathrm{MoCl}_{4}(\mathrm{THT})_{2}\right] . \mathrm{MoCl}_{5}(250 \mathrm{mg}, 0.915 \mathrm{mmol})$ was dissolved in $\mathrm{CH}_{2} \mathrm{Cl}_{2}(10 \mathrm{~mL})$. THT $(0.26 \mathrm{~mL}, 2.97 \mathrm{mmol})$ was then added with stirring for $30 \mathrm{~min}$ during which the solution changed to orange. The solution was taken to dryness in vacuo, to produce a dark orange solid. Yield: $296 \mathrm{mg}, 78 \%$. Required for $\mathrm{C}_{8} \mathrm{H}_{16} \mathrm{Cl}_{4} \mathrm{MoS}_{2}$ (414.0): C, 23.20; H, 3.89. Found: C, 23.28; $\mathrm{H}, 3.73 \%$. IR ( $\left.\mathrm{Nujol} / \mathrm{cm}^{-1}\right): 338$ (Mo-Cl). UV/vis (diffuse reflectance) $/ \mathrm{cm}^{-1}: 22$ 700, $19400,16600(\mathrm{sh})$.

trans-[$\left[\mathrm{MoCl}_{4}\left(\mathrm{Me}_{2} \mathbf{S}\right)_{2}\right] . \mathrm{MoCl}_{5}(200 \mathrm{mg}, 0.75 \mathrm{mmol})$ was dissolved in $\mathrm{CH}_{2} \mathrm{Cl}_{2}(15 \mathrm{~mL})$. Anhydrous $\mathrm{Me}_{2} \mathrm{~S}(1 \mathrm{~mL})$ was then added with stirring for $30 \mathrm{~min}$ and gave a red-orange solution. The solution was filtered and evaporated in vacuo. $n$-Hexane $(10 \mathrm{~mL})$ was added to wash the solid and then removed with a syringe. The dark orange solid was dried in vacuo. Yield: $206 \mathrm{mg}, 76 \%$. Required for $\mathrm{C}_{4} \mathrm{H}_{12} \mathrm{Cl}_{4} \mathrm{MoS}_{2}$ (360.02): C, 13.27; $\mathrm{H}, 3.34$. Found: C, $13.36 ; \mathrm{H}, 3.48 \%$. IR ( $\mathrm{Nujol} / \mathrm{cm}^{-1}$ ): 332 (Mo$\mathrm{Cl}$ ). UV/vis (diffuse reflectance) $/ \mathrm{cm}^{-1}: 22000,19400,16800$ (sh). $\mu_{\text {eff: }} 2.22$ B.M (298 K).

Orange crystals of trans- $\left[\mathrm{MoCl}_{4}\left(\mathrm{Me}_{2} \mathrm{~S}\right)_{2}\right]$ grew by allowing a $\mathrm{CH}_{2} \mathrm{Cl}_{2}$ solution to evaporate slowly in a $\mathrm{N}_{2}$ atmosphere. A few orange-red crystals were also obtained by recrystallisation of crude $\left[\mathrm{MoCl}_{4}\left(\mathrm{Me}_{2} \mathrm{~S}\right)_{2}\right]$ from $\mathrm{CH}_{2} \mathrm{Cl}_{2}$; these were found to be $\left[\mathrm{Me}_{2} \mathrm{SCH}_{2} \mathrm{SMe}\right]\left[\mathrm{MoCl}_{5}\left(\mathrm{Me}_{2} \mathrm{~S}\right)\right]$ from an X-ray structure determination.

Alternative method: $\mathrm{MoCl}_{5}(150 \mathrm{mg}, 0.55 \mathrm{mmol})$ was dissolved in MeCN $(10 \mathrm{~mL})$ with stirring to give a dark brown solution. The solution was stirred for another $10 \mathrm{~min}$ and taken to dryness to produce a dark brown solid. The solid was suspended in $\mathrm{CH}_{2} \mathrm{Cl}_{2}(10 \mathrm{~mL})$ before adding $\mathrm{Me}_{2} \mathrm{~S}(3 \mathrm{~mL})$. The suspended solid dissolved immediately after the $\mathrm{Me}_{2} \mathrm{~S}$ was added in to give a red-brown solution. The solution was stirred for another $10 \mathrm{~min}$ and then pumped to dryness, leaving a dark orange solid. The product was spectroscopically identical with the product made from $\mathrm{MoCl}_{5}$ in $\mathrm{CH}_{2} \mathrm{Cl}_{2}$.

trans $-\left[\mathrm{MoCl}_{4}\left({ }^{n} \mathrm{Bu}_{2} \mathbf{S}\right)_{2}\right] . \mathrm{MoCl}_{5}(205 \mathrm{mg}, 0.75 \mathrm{mmol})$ was dissolved in $\mathrm{CH}_{2} \mathrm{Cl}_{2}(10 \mathrm{~mL})$. A solution of ${ }^{n} \mathrm{Bu}_{2} \mathrm{~S}(274 \mathrm{mg}$, $2.5 \mathrm{mmol}$ ) in $\mathrm{CH}_{2} \mathrm{Cl}_{2}$ (ca. $3 \mathrm{~mL}$ ) was then added with stirring for $30 \mathrm{~min}$ and gave a red-orange solution. The solution was filtered and evaporated to dryness in vacuo. The residue was washed with $n$-hexane $(10 \mathrm{~mL})$, and the dark orange oil dried in vacuo. Yield: $250 \mathrm{mg}, 62 \%$. Required for $\mathrm{C}_{16} \mathrm{H}_{36} \mathrm{Cl}_{4} \mathrm{MoS}_{2}$ (526.31): C, 36.51; H, 6.13. Found: C, 36.15; H, 6.72\%. IR (Nujol/ $\mathrm{cm}^{-1}$ ): 334, 305sh (Mo-Cl). UV/vis (diffuse reflectance)/ $\mathrm{cm}^{-1}: 41$ 700, 20 900, 19 100, 18500 (sh).

Alternative method: $\mathrm{MoCl}_{5}(136 \mathrm{mg}, 0.5 \mathrm{mmol})$ was dissolved in MeCN (10 mL) with stirring for 30 min to give a dark brown solution. The solution taken to dryness in vacuo and left a dark brown solid. $\mathrm{CH}_{2} \mathrm{Cl}_{2}(15 \mathrm{~mL})$ was added, followed by a solution of ${ }^{n} \mathrm{Bu}_{2} \mathrm{~S}(0.4 \mathrm{~mL}, 2.0 \mathrm{mmol})$ in $\mathrm{CH}_{2} \mathrm{Cl}_{2}(2 \mathrm{~mL})$. The dark solution changed to red-orange immediately. The solution was then stirred for 15 min then evaporated in vacuo to afford a dark orange oil. The product was spectroscopically identical to that made from $\mathrm{MoCl}_{5}$ in $\mathrm{CH}_{2} \mathrm{Cl}_{2}$.

trans-[$\left[\mathbf{M o C l}_{4}\left(\mathrm{Me}_{2} \mathbf{S e}\right)_{2}\right] . \mathrm{MoCl}_{5}(205 \mathrm{mg}, 0.75 \mathrm{mmol})$ was suspended in $\mathrm{CH}_{2} \mathrm{Cl}_{2}(15 \mathrm{~mL})$ and $\mathrm{Me}_{2} \mathrm{Se}(196 \mathrm{mg}$. $1.96 \mathrm{mmol})$ was added with stirring for $30 \mathrm{~min}$ and produced an orangered solution. The solution was filtered and taken to dryness in vacuo. The solid was washed with $n$-hexane $(10 \mathrm{~mL})$, the washings removed with a syringe, and the residual dark orange 
powder dried in vacuo. Yield: $283 \mathrm{mg}, 77 \%$. Required for $\mathrm{C}_{4} \mathrm{H}_{12} \mathrm{Cl}_{4} \mathrm{MoSe}_{2}$ (455.81): C, 10.54; H, 2.65. Found: C, 10.69; H, 2.43\%. IR (Nujol/cm ${ }^{-1}$ ): 306 (Mo-Cl). $\mu_{\text {eff }}: 2.59$ B.M. UV/vis (diffuse reflectance)/cm ${ }^{-1}: 37$ 000, 33 300, 26 800, 21 800, 19000.

Alternative method: $\left[\mathrm{MoCl}_{4}(\mathrm{MeCN})_{2}\right](100 \mathrm{mg}, 0.31 \mathrm{mmol})$ was dissolved in $10 \mathrm{~mL} \mathrm{CH}_{2} \mathrm{Cl}_{2}$ with stirring. A solution of $\mathrm{Me}_{2} \mathrm{Se}(73 \mathrm{mg}, 0.65 \mathrm{mmol})$ and $\mathrm{CH}_{2} \mathrm{Cl}_{2}(5 \mathrm{~mL})$ was then added. The solution was stirred for $1 \mathrm{~h}$. resulting in a red-orange solution. Evaporation in vacuo left a dark orange powder. Yield: $99 \mathrm{mg}, 70 \%$. Required for $\mathrm{C}_{4} \mathrm{H}_{12} \mathrm{Cl}_{4} \mathrm{MoSe}_{2}$ (455.81): C, 10.54; $\mathrm{H}, 2.65$. Found: $\mathrm{C}, 10.61 ; \mathrm{H}, 2.54 \%$. The product was spectroscopically identical to that made from $\mathrm{MoCl}_{5}$.

trans-[ $\left.\mathbf{M o C l}_{4}\left({ }^{n} \mathbf{B u}_{2} \mathbf{S e}\right)_{2}\right] . \mathrm{MoCl}_{5}(136 \mathrm{mg}, 0.5 \mathrm{mmol})$ was dissolved in MeCN (15 mL) with stirring for 30 min to give a dark brown solution. The solution was taken to dryness in vacuo and left a dark brown solid. $\mathrm{CH}_{2} \mathrm{Cl}_{2}(25 \mathrm{~mL})$ was added, followed by a solution of ${ }^{n} \mathrm{Bu}_{2} \mathrm{Se}(193 \mathrm{mg}, 1.0 \mathrm{mmol})$ in $\mathrm{CH}_{2} \mathrm{Cl}_{2}$ ( $2 \mathrm{~mL}$ ). The dark solution changed to red-orange immediately. The solution was then stirred for $15 \mathrm{~min}$ then evaporated in vacuo to afford a dark red-orange oil. Yield: $292 \mathrm{mg}, 94 \%$. Required for $\mathrm{C}_{16} \mathrm{H}_{36} \mathrm{Cl}_{4} \mathrm{MoSe}_{2}$ (624.13): C, 30.79; H, 5.81. Found: C, 30.23; H, 6.00\%. IR (Nujol $/ \mathrm{cm}^{-1}$ ): $342 \mathrm{~s}, 305$ (sh) (Mo-Cl). UV/vis (diffuse reflectance) $/ \mathrm{cm}^{-1}: 40000,32000$, 28000,22 900, 21000.

$\left[\mathbf{M o C l}_{4}\left(\mathbf{M e S C H}_{2} \mathbf{C H}_{2} \mathbf{S M e}\right)\right] \cdot \mathrm{MoCl}_{5}(205 \mathrm{mg}, 0.75 \mathrm{mmol})$ was dissolved in $\mathrm{CH}_{2} \mathrm{Cl}_{2}(10 \mathrm{~mL})$. A solution of $\mathrm{MeSCH}_{2} \mathrm{CH}_{2} \mathrm{SMe}$ (92 $\mathrm{mg}, 0.75 \mathrm{mmol}$ ) in $\mathrm{CH}_{2} \mathrm{Cl}_{2}($ ca. $3 \mathrm{~mL}$ ) was added and the mixture stirred overnight. A deep orange solution and a brown solid formed. More $\mathrm{CH}_{2} \mathrm{Cl}_{2}(10 \mathrm{~mL})$ was added and the solution was filtered. The filtrate was evaporated to dryness in vacuo. $n$-Hexane $(10 \mathrm{~mL})$ was added to wash the solid and subsequently removed by a syringe. The solid was dried in vacuo to give a dark orange solid. Yield: $157 \mathrm{mg}, 58 \%$. IR ( $\left.\mathrm{Nujol} / \mathrm{cm}^{-1}\right)$ : 356, 319, 293 (Mo-Cl). UV/vis (diffuse reflectance) $/ \mathrm{cm}^{-1}$ : 41 500, 27 300, 21 000, 19600. $\mu_{\text {eff }}$ 2.66 B.M. Orange crystals grew on allowing a $\mathrm{CH}_{2} \mathrm{Cl}_{2}$ solution to evaporate in a $\mathrm{N}_{2}$ atmosphere.

Alternative method: $\mathrm{MoCl}_{5}(136 \mathrm{mg}, 0.5 \mathrm{mmol})$ was dissolved in MeCN (10 mL) with stirring for 10 min to give a dark brown solution. The solution taken to dryness in vacuo, $\mathrm{CH}_{2} \mathrm{Cl}_{2}(10 \mathrm{~mL})$ was added, followed by a solution of $\mathrm{MeSCH}_{2} \mathrm{CH}_{2} \mathrm{SMe}(180 \mathrm{mg}, 1.5 \mathrm{mmol})$ in $\mathrm{CH}_{2} \mathrm{Cl}_{2}(2 \mathrm{~mL})$. The dark solution changed to light orange-green immediately and deposited a brown solid, which was filtered off. The brown solid was dried in vacuo and washed with $\mathrm{Et}_{2} \mathrm{O}(c a .5 \mathrm{~mL})$, then extracted with $\mathrm{CH}_{2} \mathrm{Cl}_{2}$ (ca. $\left.5 \mathrm{~m}\right)$. The resulting solution was again taken to dryness in vacuo. Yield: $60 \mathrm{mg}, 33 \%$. Required for $\mathrm{C}_{4} \mathrm{H}_{10} \mathrm{Cl}_{4} \mathrm{MoS}_{2} \cdot 0.1 \mathrm{Et}_{2} \mathrm{O}$ (367.4): C, 14.38; H, 3.02. Found: C, $14.38 ; \mathrm{H}, 3.02 \%$ (sample contained ca. $10 \% \mathrm{Et}_{2} \mathrm{O}$ from wash solvent; this was identified via $^{1} \mathrm{H}$ NMR spectroscopy).

$\left[\mathbf{M o C l}_{4}\left({ }^{\mathrm{i}} \mathbf{P r S C H}_{2} \mathbf{C H}_{2} \mathbf{S}^{\mathrm{i}} \mathbf{P r}\right)\right] . \mathrm{MoCl}_{5}(136 \mathrm{mg}, 0.5 \mathrm{mmol})$ was dissolved in $\mathrm{CH}_{3} \mathrm{CN}(10 \mathrm{~mL})$ forming dark brown solution. The solution was stirred for $10 \mathrm{~min}$ and then evaporated in vacuo, giving dark brown solid. The solid was dissolved in $\mathrm{CH}_{2} \mathrm{Cl}_{2}$ $(15 \mathrm{~mL})$ and a solution of ${ }^{\mathrm{i}} \mathrm{PrSCH}_{2} \mathrm{CH}_{2} \mathrm{~S}{ }^{\mathrm{i}} \mathrm{Pr}(270 \mathrm{mg}, 1.5 \mathrm{mmol})$ in $\mathrm{CH}_{2} \mathrm{Cl}_{2}(2 \mathrm{~mL})$ was added. The colour changed to orange and solid formed immediately. The solution was stirred for $30 \mathrm{~min}$ and then evaporated in vacuo. The solid was washed with $\mathrm{Et}_{2} \mathrm{O}(5 \mathrm{~mL})$, the $\mathrm{Et}_{2} \mathrm{O}$ removed via a syringe, and the solid was dried in vacuo. Orange powder. Yield: $160 \mathrm{mg}, 77 \%$. Required for $\mathrm{C}_{8} \mathrm{H}_{18} \mathrm{Cl}_{4} \mathrm{MoS}_{2}$ (416.11): C, 23.09; H, 4.36. Found: C, 23.90; H, 4.56\%. IR ( $\mathrm{Nujol} / \mathrm{cm}^{-1}$ ): 371sh, 350, 309 (Mo-Cl).

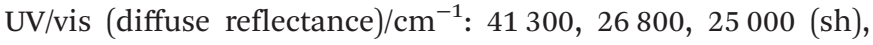
21000,18700 (sh). $\mu_{\text {eff: }} 2.18$ B.M. Orange red crystals grew by allowing a $\mathrm{CH}_{2} \mathrm{Cl}_{2}$ solution to evaporate slowly under $\mathrm{N}_{2}$.

$\left[\mathbf{M o C l}_{4}\left(\mathbf{M e S C H}_{2} \mathbf{C H}_{2} \mathbf{C H}_{2} \mathbf{S M e}\right)\right] . \mathbf{M o C l}_{5}(205 \mathrm{mg}, 0.75 \mathrm{mmol})$ was suspended in $\mathrm{CH}_{2} \mathrm{Cl}_{2}(20 \mathrm{~mL})$ and a solution of $\mathrm{MeSCH}_{2} \mathrm{CH}_{2} \mathrm{CH}_{2} \mathrm{SMe}(109 \mathrm{mg}, 0.8 \mathrm{mmol})$ in $\mathrm{CH}_{2} \mathrm{Cl}_{2}$ (ca. $3 \mathrm{~mL}$ ) was added, and stirred overnight to give an orange solution and some orange solid. The solution was removed by a syringe, and the solid washed with $n$-hexane $(10 \mathrm{~mL})$. The solid was subsequently dried in vacuo. Yield: $83 \mathrm{mg}, 30 \%$. Required for $\mathrm{C}_{5} \mathrm{H}_{12} \mathrm{Cl}_{4} \mathrm{MoS}_{2}$ (374.03): C, 16.06; H, 3.23. Found: C, 16.22; $\mathrm{H}, 3.35 \%$. IR ( Nujol $\left./ \mathrm{cm}^{-1}\right): 362,342,327$ (Mo-Cl). UV/vis (diffuse reflectance) $/ \mathrm{cm}^{-1}: 40500,22070,19500 . \mu_{\text {eff: }} 2.21$ B.M. Orange crystals grew by allowing a $\mathrm{CH}_{2} \mathrm{Cl}_{2}$ solution to evaporate under $\mathrm{N}_{2}$.

$\left[\mathbf{M o C l}_{4}\left(\mathrm{MeSeCH}_{2} \mathbf{C H}_{2} \mathbf{C H}_{2} \mathrm{SeMe}\right)\right]$. Was made as described for $\left[\mathrm{MoCl}_{4}\left({ }^{\mathrm{i}} \mathrm{PrSCH}_{2} \mathrm{CH}_{2} \mathrm{~S}^{\mathrm{i}} \mathrm{Pr}\right)\right]$ and obtained as a light orange powder. Yield: $59 \%$. Required for $\mathrm{C}_{5} \mathrm{H}_{12} \mathrm{Cl}_{4} \mathrm{MoSe}_{2}$ (467.82): C, 12.84; H, 2.59. Found: C, 13.01; H, 2.57\%. IR ( $\left.\mathrm{Nujol} / \mathrm{cm}^{-1}\right)$ : 332, 308 (Mo-Cl). UV/vis (diffuse reflectance) $/ \mathrm{cm}^{-1}: 41100$, $26800,21000,18700$.

LPCVD of $\mathrm{MoS}_{2}$ films using $\left[\mathrm{MoCl}_{4}\left({ }^{n} \mathrm{Bu}_{2} \mathrm{~S}\right)_{2}\right]$. The precursor (190 mg) dissolved in $\mathrm{CH}_{2} \mathrm{Cl}_{2}(1 \mathrm{~mL})$ was loaded into the closed end of a silica tube in an $\mathrm{N}_{2}$ purged glove box, and the solvent removed. Silica substrates (ca. $\left.1 \times 8 \times 20 \mathrm{~mm}^{3}\right)$ were then loaded in the tube and placed end-to-end. The tube was set in a furnace so that the substrates were in the heated zone and the precursor was $c a .2 \mathrm{~cm}$ away from the start of the heated zone. The tube was evacuated to $0.1 \mathrm{~mm} \mathrm{Hg}$, and the furnace was heated to $750{ }^{\circ} \mathrm{C}$ and left for 10 minutes to allow the temperature to stabilise. The tube was gradually moved into the hot zone until evaporation of the precursor began to occur. The position was then maintained until the all the precursor had evaporated. A yellow/orange film was observed at the opposite end of the tube (S). After ca. 30 min the tube was cooled to room temperature and the tiles were unloaded at ambient temperature in a dinitrogen atmosphere. Silver films were observed on the first two substrates, which corresponds to $735{ }^{\circ} \mathrm{C}$ (determined by temperature profiling). The silver films are identical by grazing incidence and in-plane XRD and SEM/EDX analysis.

$\mathbf{M o S e}_{2}$ films using $\left[\mathrm{MoCl}_{4}\left({ }^{n} \mathrm{Bu}_{2} \mathrm{Se}\right)_{2}\right]$. Using the same deposition procedure and with $\mathrm{ca} .50 \mathrm{mg}$ of precursor complex. Depositions were undertaken with the furnace temperature set at $400,450,500$ and $500{ }^{\circ} \mathrm{C}$. A red (Se) film was observed at the far end of the tube and all experiments produced golden/ brown films on the substrates. Temperature profiling for the best $\mathrm{MoSe}_{2}$ films confirmed that the actual deposition temperature was $535{ }^{\circ} \mathrm{C}$. Using larger precursor quantities (ca. $200 \mathrm{mg}$ ) led to thicker films being formed. 


\section{Film characterisation}

$\mathrm{X}$-Ray diffraction (XRD) patterns were collected in grazing incidence mode $\left(\theta_{1}=1^{\circ}\right)$ or in-plane mode $\left(\theta_{1}=0.5^{\circ}, 2 \theta_{\chi}\right.$ scan with the detector scanning in the film plane) using a Rigaku SmartLab diffractometer $\left(\mathrm{Cu}-\mathrm{K}_{\alpha}, \lambda=1.5418 \AA\right)$ with parallel X-ray beam and a DTex Ultra 250 1D detector. Phase matching, lattice parameter calculations $\left(\mathrm{MoS}_{2}\right)$ and Le Bail fitting $\left(\mathrm{MoSe}_{2}\right)$ used the PDXL2 software package ${ }^{27}$ and diffraction patterns from ICSD. ${ }^{28}$ Scanning electron microscopy (SEM) was performed on samples at an accelerating voltage of 10 to $15 \mathrm{kV}$ using a JEOL JSM6500 or a Philips XL30 ESEM. Film thicknesses were measured by fracturing the substrate and gold sputtering the edge in order to control charging of the insulating silica surface. Energy dispersive X-ray (EDX) analysis data were obtained with an Oxford INCA x-act X-ray detector (JSM6500) or Thermofisher Ultradry NSS 3 (XL30). Raman spectra were collected using a Renishaw InVia Raman Microscope with a $100 \mathrm{~mW}$ He-Ne 785 nm Laser. Optical spectra were obtained in transmission mode using a PerkinElmer 750S UV-visible spectrometer.

\section{Results and discussion}

Two routes were used to prepare the $\mathrm{MoCl}_{4}$ complexes (Scheme 1), either substitution of the MeCN ligands in trans$\left[\mathrm{MoCl}_{4}(\mathrm{MeCN})_{2}\right]$ with the chalcogenoether ligand in $\mathrm{CH}_{2} \mathrm{Cl}_{2}$ solution or reaction of $\mathrm{MoCl}_{5}$ with excess ligand in $\mathrm{CH}_{2} \mathrm{Cl}_{2}$.

$\left[\mathrm{MoCl}_{4}(\mathrm{RCN})_{2}\right]\left(\mathrm{R}=\mathrm{Me}\right.$, Et, $\left.{ }^{n} \mathrm{Pr}\right)$ are well known starting materials $^{29-31}$ and an X-ray crystal structure determination of the complex with $\mathrm{R}=$ Me showed it to be the trans isomer (see Fig. S1, ESI $\dagger$ ). The crystals are isomorphous with trans$\left[\mathrm{WCl}_{4}(\mathrm{MeCN})_{2}\right]{ }^{31}$ In the preparations using $\mathrm{MoCl}_{5}$, the chalcogen ligand reduces the molybdenum centre, being halogenated in the process, and careful washing is needed to remove the by-products. A few crystals of a minor by-product from the synthesis of $\left[\mathrm{MoCl}_{4}\left(\mathrm{Me}_{2} \mathrm{~S}\right)_{2}\right]$ from $\mathrm{MoCl}_{5}$ were identified by a

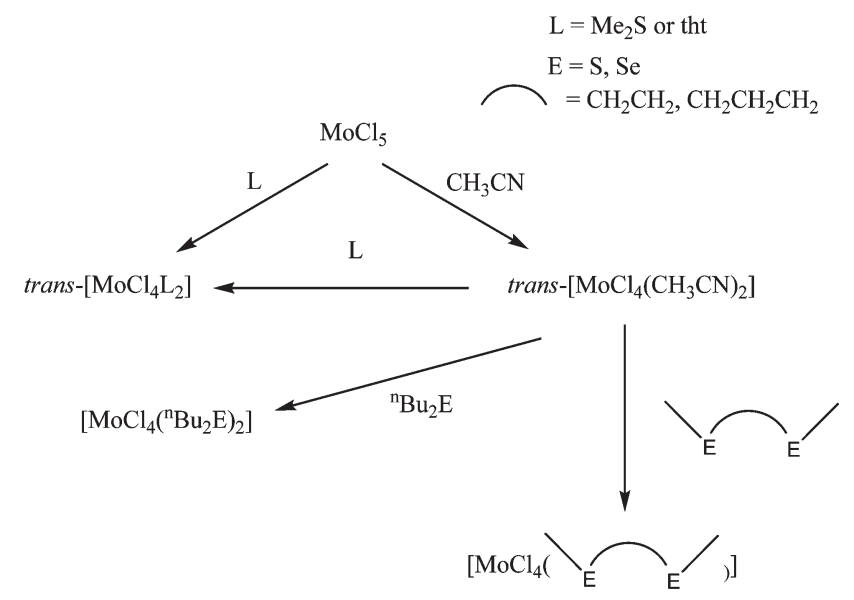

Scheme 1 The preparative routes to the $\mathrm{MoCl}_{4}$ chalcogenoether complexes.
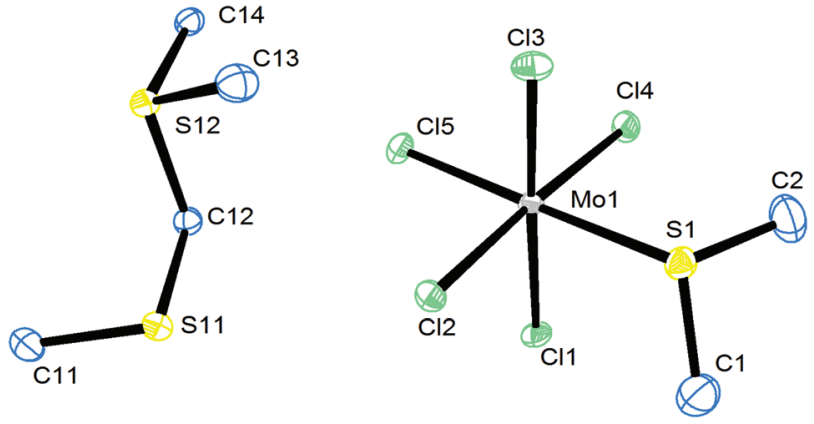

Fig. 1 The structure of one of the two crystallographically independent cations and molybdenum anions in $\left[\mathrm{Me}_{2} \mathrm{SCH}_{2} \mathrm{SMe}\right]\left[\mathrm{MoCl}_{5}\left(\mathrm{Me}_{2} \mathrm{~S}\right)\right]$ showing the atom numbering scheme and with ellipsoids drawn at the $50 \%$ probability level. The other cation and anion are very similar. Hydrogen atoms are omitted for clarity. Selected bond lengths $(\AA \AA)$ and angles $\left({ }^{\circ}\right)$ : Mo1-Cl4 = 2.3251(17), Mo1-Cl1 = 2.3509(17), $\mathrm{Mo1}-\mathrm{Cl} 3=$ 2.3633(18), Mo1-Cl5 = 2.3847(18), Mo1-Cl2 = 2.3885(17), Mo1-S1 = 2.5538(19), (cis) $\mathrm{Cl}-\mathrm{Mo}-\mathrm{Cl}=88.10(6)-92.87(7), \mathrm{Cl}-\mathrm{Mo1}-\mathrm{S} 1=83.14(6)-$ $91.74(6)$.

crystal structure determination as the sulfonium salt, $\left[\mathrm{Me}_{2} \mathrm{SCH}_{2} \mathrm{SMe}\right]\left[\mathrm{MoCl}_{5}\left(\mathrm{Me}_{2} \mathrm{~S}\right)\right]$ (Fig. 1). This cation has also been identified as a product of reaction of $\mathrm{MoCl}_{5}$ with DMSO; ${ }^{32}$ in the latter case it was obtained with an $\left[\mathrm{MoOCl}_{4}\right]^{-}$ anion. $^{32}$

The isolated, coordinatively saturated $\mathrm{MoCl}_{4} \mathrm{~L}_{2}$ complexes are mildly hydrolytically sensitive. The crystal structures were determined for trans-[ $\left.\mathrm{MoCl}_{4}\left(\mathrm{Me}_{2} \mathrm{~S}\right)\right]$, cis-[ $\left.\mathrm{MoCl}_{4}\left\{\mathrm{RS}\left(\mathrm{CH}_{2}\right)_{2} \mathrm{SR}\right\}\right]$ $\left(\mathrm{R}=\mathrm{Me},{ }^{\mathrm{i}} \mathrm{Pr}\right)$ and cis-[ $\left.\mathrm{MoCl}_{4}\left\{\mathrm{MeS}\left(\mathrm{CH}_{2}\right)_{3} \mathrm{SMe}\right\}\right]$ and show the expected six-coordinate geometries (Fig. 2-4), with the chelate bite of the dithioethers responsible for the deviations from regular octahedral geometry. The bond lengths are similar to those in related Mo(Iv) complexes. ${ }^{19,20,33}$

The complexes are paramagnetic with $\mu_{\text {eff }}$ in the range 2.0-2.7 B.M. The values are lower than the predicted spin-only value for $\mathrm{a} \mathrm{d}^{2}$ ion (2.82 B.M.) due to the significant spin-orbit coupling, as expected for $4 \mathrm{~d}$ elements, ${ }^{34}$ and are similar to

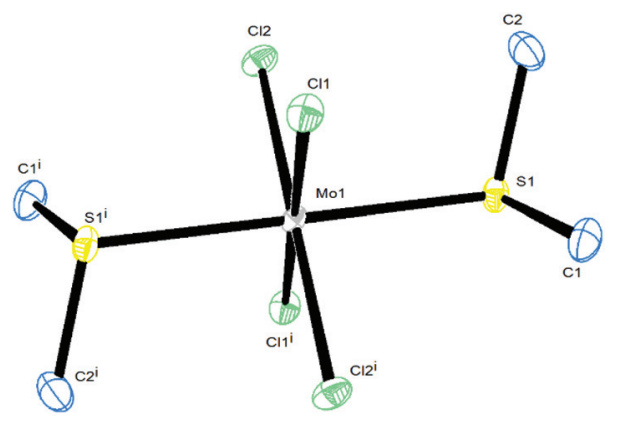

Fig. 2 The structure of the centrosymmetric $\left[\mathrm{MoCl}_{4}\left(\mathrm{Me}_{2} \mathrm{~S}\right)_{2}\right]$ showing the atom numbering scheme and with ellipsoids drawn at the $50 \%$ probability level. Hydrogen atoms are omitted for clarity. Symmetry operation: $\mathrm{i}=-x,-y,-z+1$. Selected bond lengths $(\AA \AA)$ and angles $\left({ }^{\circ}\right)$ : Mo1$\mathrm{Cl} 1=2.3457(5), \mathrm{Mo1}-\mathrm{Cl} 2$ = 2.3323(5), Mo1-S1 = 2.5297(6); Cl1-Mo1$\mathrm{Cl} 2=89.39(2), \mathrm{Cl} 1^{\mathrm{i}}-\mathrm{Mo1}-\mathrm{Cl} 2^{\mathrm{i}}=90.61(2), \mathrm{Cl} 1-\mathrm{Mo1}-\mathrm{S1}^{\mathrm{i}}=88.65(2), \mathrm{Cl}^{\mathrm{i}}-$ $\mathrm{Mo1}-\mathrm{S} 1^{\mathrm{i}}=91.35(2), \mathrm{Cl}-\mathrm{Mo} 1-\mathrm{S} 1=90.51(2), \mathrm{Cl} 2^{\mathrm{i}}-\mathrm{Mo1}-\mathrm{S} 1=89.49(2)$. 


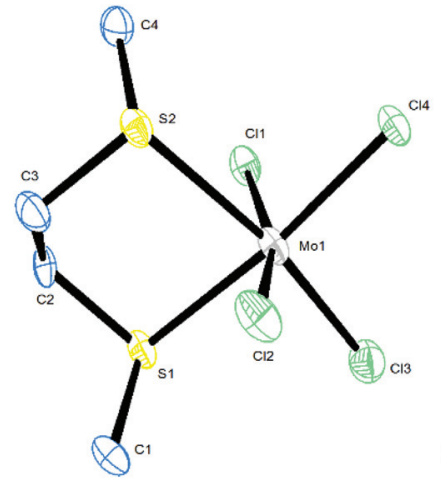

(a)

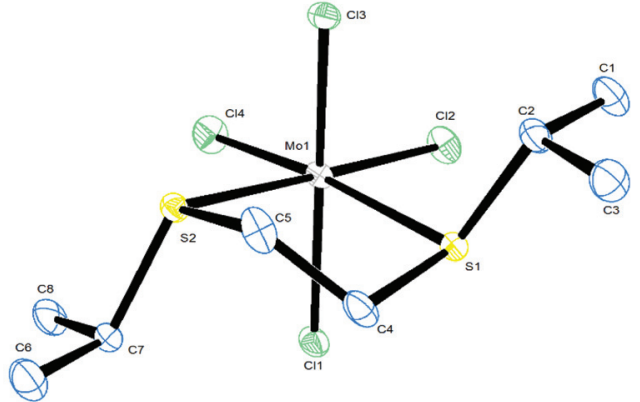

(b)

Fig. 3 (a) The structure of $\left[\mathrm{MoCl}_{4}\left(\mathrm{MeSCH}_{2} \mathrm{CH}_{2} \mathrm{SMe}\right)\right]$ showing the atom numbering scheme and with ellipsoids drawn at the $50 \%$ probability level. Hydrogen atoms are omitted for clarity. Selected bond lengths $(\AA \AA)$ and angles $\left({ }^{\circ}\right)$ : $\mathrm{Mo1}-\mathrm{Cl} 3=2.247(3), \mathrm{Mo1}-\mathrm{Cl} 1=2.305(3), \mathrm{Mo1}-\mathrm{Cl} 2=2.305(3)$, $\mathrm{Mo1}-\mathrm{Cl} 4=2.339(3), \mathrm{Mo1}-\mathrm{S} 1=2.519(3), \mathrm{Mo1}-\mathrm{S} 2=2.591(3), \mathrm{Cl} 3-\mathrm{Mo1}-\mathrm{Cl1}=97.61(12), \mathrm{Cl} 3-\mathrm{Mo1}-\mathrm{Cl} 2=98.42(13), \mathrm{Cl} 3-\mathrm{Mo1}-\mathrm{Cl} 4=96.83(11), \mathrm{Cl} 1-$ $\mathrm{Mo1}-\mathrm{Cl} 4=92.47(10), \mathrm{Cl} 2-\mathrm{Mo1}-\mathrm{Cl} 4=92.95(10), \mathrm{Cl} 3-\mathrm{Mo1}-\mathrm{S} 1=87.75(11), \mathrm{Cl} 1-\mathrm{Mo1}-\mathrm{S} 1=82.18(10), \mathrm{Cl}-\mathrm{Mo1}-\mathrm{S} 1=91.07(10), \mathrm{Cl}-\mathrm{Mo1}-\mathrm{S} 2=$ $85.34(10), \mathrm{Cl} 2-\mathrm{Mo1}-\mathrm{S} 2=77.66(11), \mathrm{Cl} 4-\mathrm{Mo1}-\mathrm{S} 2=92.13(10), \mathrm{S} 1-\mathrm{Mo1}-\mathrm{S} 2=83.62(9)$. (b) The structure of $\left[\mathrm{MoCl}_{4}\left({ }^{\mathrm{I}} \mathrm{PrSCH} \mathrm{CH}_{2} \mathrm{CH}_{2} \mathrm{P} P\right.\right.$ ) $]$ showing the atom numbering scheme and with ellipsoids drawn at the $50 \%$ probability level. Hydrogen atoms are omitted for clarity. Selected bond lengths ( $\AA$ ) and angles $\left({ }^{\circ}\right)$ : $\mathrm{Mo} 1-\mathrm{Cl} 1=2.3203(7), \mathrm{Mo1}-\mathrm{Cl} 2=2.3295(7), \mathrm{Mo1}-\mathrm{Cl} 3=2.3135(7), \mathrm{Mo1}-\mathrm{Cl} 4=2.3016(7), \mathrm{Mo}-1 \mathrm{~S} 1=2.5872(7), \mathrm{Mo1}-\mathrm{S} 2=2.5730(7) ; \mathrm{Cl} 2-$ $\mathrm{Mo1}-\mathrm{Cl} 4=93.37(3), \mathrm{Cl} 4-\mathrm{Mo1}-\mathrm{Cl} 3=97.30(3), \mathrm{Cl} 4-\mathrm{Mo1}-\mathrm{Cl} 1=96.60(3), \mathrm{Cl} 3-\mathrm{Mo1}-\mathrm{Cl} 2=96.57(3), \mathrm{Cl} 1-\mathrm{Mo1}-\mathrm{Cl} 2=96.14(3), \mathrm{Cl} 4-\mathrm{Mo1}-\mathrm{S} 2=92.81(3)$, $\mathrm{Cl} 3-\mathrm{Mo1}-\mathrm{S} 2$ = 79.16(2), Cl1-Mo1-S2 = 86.63(2), Cl3-Mo1-S1 = 87.01(2), Cl1-Mo1-S1 = 78.40(2), Cl2-Mo1-S1 = 89.61(2), S2-Mo1-S1 = 84.52(2).

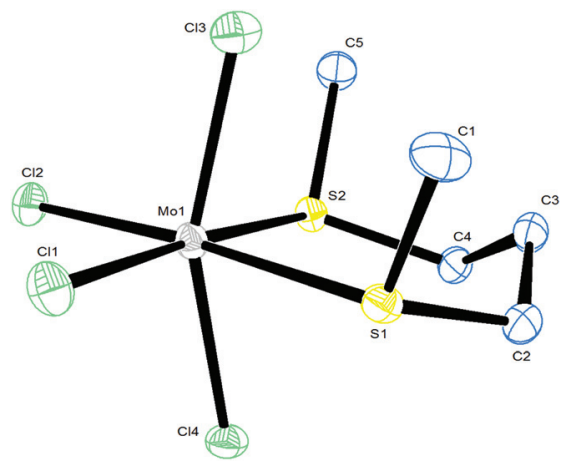

Fig. 4 The structure of $\left[\mathrm{MoCl}_{4}\left(\mathrm{MeSCH}_{2} \mathrm{CH}_{2} \mathrm{CH}_{2} \mathrm{SMe}\right)\right]$ showing the atom numbering scheme and with ellipsoids drawn at the $50 \%$ probability level. Hydrogen atoms are omitted for clarity. Selected bond lengths $(\AA)$ and angles $\left({ }^{\circ}\right)$ : Mo1- $\mathrm{Cl} 3=2.2686(6)$, Mo1- $\mathrm{Cl} 1=2.3143(6)$, $\mathrm{Mo} 1-\mathrm{Cl} 4=2.3380(6), \mathrm{Mo} 1-\mathrm{Cl} 2=2.3486(6), \mathrm{Mo1}-\mathrm{S} 1=2.5282(6), \mathrm{Mo1}-$ $\mathrm{S} 2=2.5390(6), \mathrm{Cl} 3-\mathrm{Mo1}-\mathrm{Cl} 1=98.40(2), \mathrm{Cl} 1-\mathrm{Mo1}-\mathrm{Cl} 4=97.61(2), \mathrm{Cl} 3-$ $\mathrm{Mo} 1-\mathrm{Cl} 2=96.29(2), \mathrm{Cl} 1-\mathrm{Mo1}-\mathrm{Cl} 2=92.82(2), \mathrm{Cl} 4-\mathrm{Mo1}-\mathrm{Cl} 2=97.58(2)$, $\mathrm{Cl} 3-\mathrm{Mo}-1 \mathrm{~S} 1=87.41(2), \mathrm{Cl} 1-\mathrm{Mo} 1-\mathrm{S} 1=83.61(2), \mathrm{Cl} 4-\mathrm{Mo1}-\mathrm{S} 1=$ $79.79(2), \mathrm{Cl} 3-\mathrm{Mo1}-\mathrm{S} 2$ = 86.13(2), Cl4-Mo1-S2 = 78.20(2), Cl2-Mo1-S2 = 85.94(2), S1-Mo1-S2 = 97.370(19).

those observed in related complexes. ${ }^{18-20,29,33}$ The solid state UV/visible spectra exhibit two overlapping bands in the range 18 000-22 $000 \mathrm{~cm}^{-1}$, which can be assigned in approximate $O_{\mathrm{h}}$ symmetry as the $\mathrm{d}-\mathrm{d}$ transitions, ${ }^{3} \mathrm{~T}_{1 \mathrm{~g}} \rightarrow{ }^{3} \mathrm{~T}_{1 \mathrm{~g}}(\mathrm{P})$ and ${ }^{3} \mathrm{~T}_{1 \mathrm{~g}} \rightarrow$ ${ }^{3} \mathrm{~T}_{2 \mathrm{~g}},{ }^{35}$ with ill-defined charge transfer transitions evident at $>30000 \mathrm{~cm}^{-1}$.

\section{CVD of molybdenum dichalcogenide films}

The thermal decomposition of the $\left[\mathrm{MoCl}_{4}\left({ }^{n} \mathrm{Bu}_{2} \mathrm{E}\right)_{2}\right]$ complexes at atmospheric pressure was first probed using thermo-

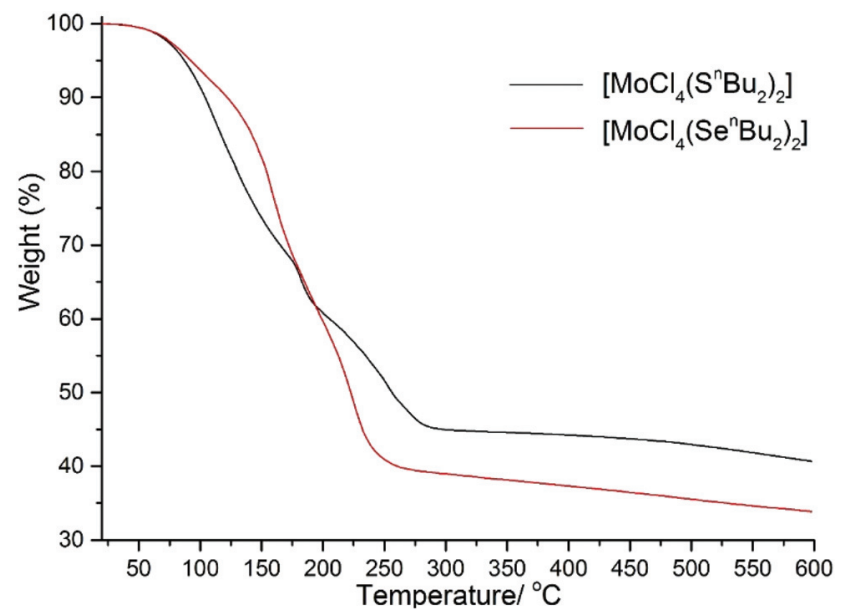

Fig. 5 TGA of $\left[\mathrm{MoCl}_{4}\left({ }^{n} \mathrm{Bu}_{2} \mathrm{E}\right)_{2}\right](\mathrm{E}=\mathrm{S}$ or Se) obtained under flowing $\mathrm{Ar}$ $\left(65 \mathrm{~mL} \mathrm{~min}{ }^{-1}\right)$ at ambient pressure with a heating rate of $10^{\circ} \mathrm{C} \mathrm{min}^{-1}$.

gravimetric analysis (TGA). $\left[\mathrm{MoCl}_{4}\left({ }^{n} \mathrm{Bu}_{2} \mathrm{Se}\right)_{2}\right]$ underwent three mass loss steps at $75-125{ }^{\circ} \mathrm{C}, 180-200{ }^{\circ} \mathrm{C}$ and $200-280{ }^{\circ} \mathrm{C}$, leaving a residual mass of $c a .39 .4 \%$, which gradually reduced further as the temperature was raised to $600{ }^{\circ} \mathrm{C}$ (Fig. 5). This suggests a complex decomposition pathway with $\mathrm{MoSe}_{2}$ $(40.7 \%)$ or $\mathrm{MoCl}_{4}(38 \%)$ as the final residue. $\left[\mathrm{MoCl}_{4}\left({ }^{n} \mathrm{Bu}_{2} \mathrm{~S}\right)_{2}\right]$ also shows three mass loss steps at $25-160{ }^{\circ} \mathrm{C}, 170-200^{\circ} \mathrm{C}$ and 210-300 ${ }^{\circ} \mathrm{C}$, leaving a residual mass of $c a .44 .9 \%$, which undergoes a further small mass loss (ca. $5 \%$ ) on heating to $600{ }^{\circ} \mathrm{C}$ (Fig. 5). The residual mass is higher than that expected for $\mathrm{MoS}_{2}$ (30\%), but similar to that expected for $\mathrm{MoCl}_{4}(44.7 \%)$; some sublimation of $\mathrm{MoCl}_{4}$ at high temperature would be expected; we note that $\left[\mathrm{NbCl}_{4}\left({ }^{n} \mathrm{Bu}_{2} \mathrm{~S}\right)_{2}\right]$ left $\mathrm{NbCl}_{4}$ upon heating 
in vacuo. ${ }^{36}$ It is important to note that the TGA experiments are performed at 1 atmosphere pressure under flowing argon, and hence very different from LPCVD conditions. However, TGA does provide a guide to the volatility of the precursors.

CVD test experiments focussed on those complexes bearing ${ }^{n} \mathrm{Bu}$ substituents since, unlike Me substituents, these tend to be promote elimination of the organic by-products, most likely via $\beta$-hydride elimination reactions. CVD onto silica tiles using ca. $30-70 \mathrm{mg}$ of the $\left[\mathrm{MoCl}_{4}\left({ }^{n} \mathrm{Bu}_{2} \mathrm{Se}\right)_{2}\right]$ precursor resulted in deposition of a reflective golden film on tiles positioned in the hottest part of the furnace at $400-550{ }^{\circ} \mathrm{C}$. Grazing incidence XRD (Fig. 6) showed these films to be the $2 \mathrm{H}$ form of $\mathrm{MoSe}_{2}$ $\left(P 6_{3} / m m c\right)$. Lattice parameters determined from a Le Bail fit to the pattern are $a=3.2666(10)$ and $c=13.170(16) \AA\left(R_{\mathrm{wp}}=1.8 \%\right.$, $R_{\mathrm{p}}=1.3 \%$; see ESI Fig. $\mathrm{S} 2 \uparrow$ for fit). The lattice parameters listed in ICSD for this phase are in the ranges $a=3.288-3.290$ and $c=12.90-12.94 \AA^{28}{ }^{28}$ The films are air and moisture stable (over many months), but easily scratched with a metal spatula. With deposition temperatures higher than $550{ }^{\circ} \mathrm{C}, \mathrm{MoO}_{2}$ thin films were recovered, presumably resulting from deposition of

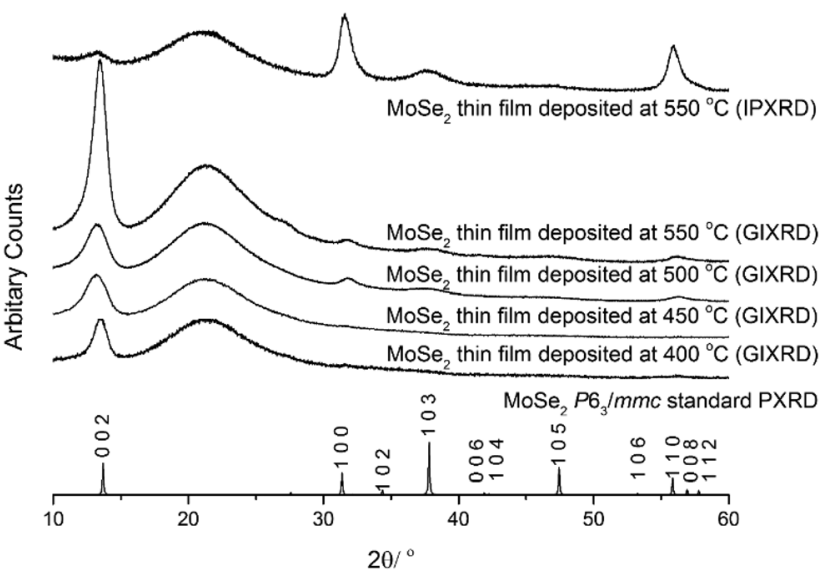

Fig. 6 Grazing incidence XRD (GIXRD, incidence angle $=1^{\circ}$ ) and inplane XRD (IPXRD, incidence angle $=0.5^{\circ}$ ) from $\mathrm{MoSe}_{2}$ thin films deposited by CVD from $\left[\mathrm{MoCl}_{4}\left({ }^{n} \mathrm{Bu}_{2} \mathrm{Se}\right)_{2}\right]$ at temperatures as shown. The broad feature at $2 \theta \sim 22^{\circ}$ is from the $\mathrm{SiO}_{2}$ substrate. The calculated pattern for bulk polycrystalline $2 \mathrm{H}-\mathrm{MoSe}_{2}\left(\mathrm{PG}_{3} / \mathrm{mmc}\right)$ with Miller indices is shown for comparison. ${ }^{28}$ molybdenum metal that oxidised post-deposition. Parkin and co-workers previously deposited films containing a mixture of the $2 \mathrm{H}$ - and 3R-type $\mathrm{MoSe}_{2}$ films using dual source atmospheric pressure CVD, ${ }^{16}$ but we are not aware of any other reports of single phase $\mathrm{MoSe}_{2}$ films from CVD from molybdenum chloride derived precursors.

The grazing incidence diffraction patterns of the $\mathrm{MoSe}_{2}$ films are dominated by the 002 reflection, suggesting $<00 l>$ alignment of the crystallites. These layered materials typically grow as platelet-shaped crystallites with the $a b$ crystallographic axes in the plane of the crystallites, so this would suggest platelets lying flat on the substrate. An in-plane XRD measurement (Fig. 6) supressed the 002 reflection and enhanced the 100 and 110, supporting this conclusion. SEM images (Fig. 7) showed mainly the edges of platelets suggesting they were standing on edge rather than lying flat, but imaging the edge of a cross-section showed a dense, flat film with thickness of around $130 \mathrm{~nm}$ underlying these orthogonally oriented platelets. A pole figure measurement (Fig. 8) taken with $2 \theta=13.54^{\circ}$ (002 reflection) exhibits a single and sharp peak (FWHM $\sim 10^{\circ}$ ) with $\alpha=90^{\circ}$, consistent with the vast majority of crystallites adopting the $\langle 00 l\rangle$ orientation. The pole figure with $2 \theta=$ $56.10^{\circ}$ (110 reflection), exhibits a ring with $\alpha$ close to zero (the edge of the peak is cut off as the measurement cannot be made right at the substrate plane), also consistent with the $<00 l>$ preferred orientation. Unfortunately, the pole figure at the 103 reflection position was featureless. This may suggest stacking errors reducing its intensity.

Energy dispersive X-ray (EDX) analysis data showed significant $\mathrm{Si}$ and $\mathrm{O}$ from the substrate, in addition to peaks due to Mo and Se, indicating that the films are thin. There was no evidence for any residual $\mathrm{Cl}$ in the films. The Mo:Se ratio was quantified as $1: 1.9$, consistent within error with the formation of $\mathrm{MoSe}_{2}$.

The crystallite size in the $\mathrm{MoSe}_{2}$ film produced at $550{ }^{\circ} \mathrm{C}$ was calculated from the grazing incidence XRD data using the Williamson-Hall method. The 6.6(9) $\mathrm{nm}$ size that resulted is much smaller than the largest dimensions of the platelets observed in Fig. 7 ( $c a .100 \mathrm{~nm}$ ), but the observed preferred orientation shows the bulk of the material to be contained within the dense underlying film. The diffraction crystallite size appears to be dominated by this part of the sample. Using a larger amount of precursor (ca. $200 \mathrm{mg}$ ) resulted in thicker
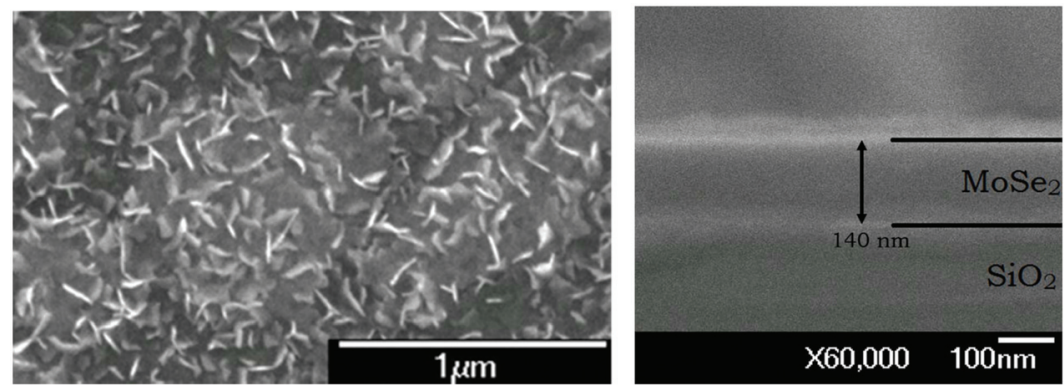

Fig. 7 SEM images of $\mathrm{MoSe}_{2}$ films produced by CVD using $\sim 70 \mathrm{mg}\left[\mathrm{MoCl}_{4}\left({ }^{n} \mathrm{Bu}_{2} \mathrm{Se}\right)_{2}\right]$ at $550{ }^{\circ} \mathrm{C}$. Top view (left) and cross-section (right). 

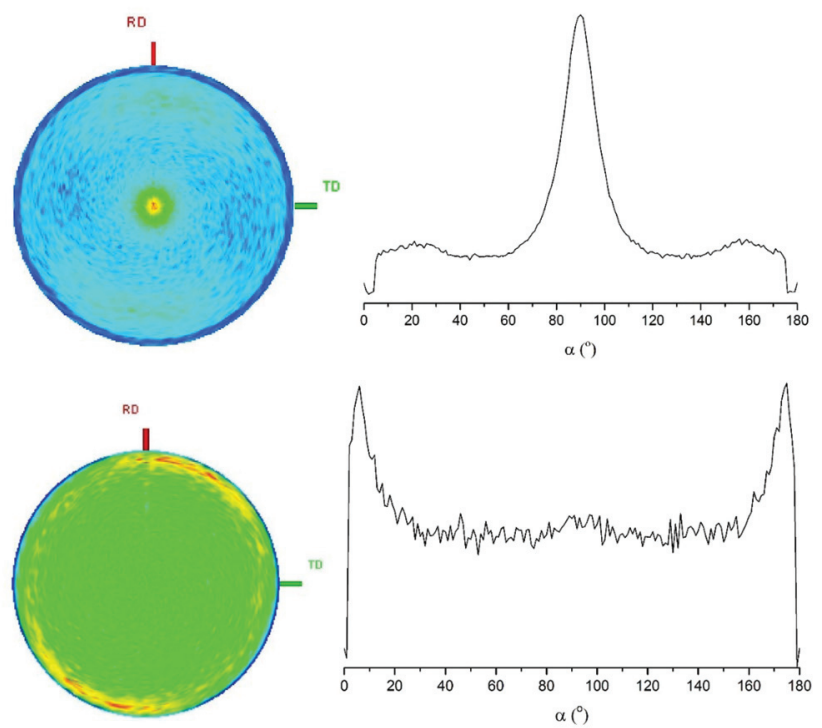

Fig. 8002 (top) and 110 (bottom) pole figure measurements shown as $2 \mathrm{D}$ plots (left) and integrated plots with $\alpha$ (right) for $\mathrm{MoSe}_{2}$ thin films produced by CVD using $\sim 70 \mathrm{mg}\left[\mathrm{MoCl}_{4}\left({ }^{n} \mathrm{Bu}_{2} \mathrm{Se}\right)_{2}\right]$ at $550{ }^{\circ} \mathrm{C}$.

films, but the optical quality of the films became worse. SEM images (ESI, Fig. S3†) showed that some crystallites continued to grow preferentially and thus the film thickness was less consistent over the area of the film.

The Raman spectrum from the $\mathrm{MoSe}_{2}$ film was collected using $785 \mathrm{~nm}$ excitation and shows three peaks at 140, 241 and $290 \mathrm{~cm}^{-1}$ assigned to the $\mathrm{E}_{1 \mathrm{~g}}, \mathrm{~A}_{1 \mathrm{~g}}$ and $\mathrm{E}_{2 \mathrm{~g}}$ vibration modes of $2 \mathrm{H}-\mathrm{MoSe}_{2}$, respectively (Fig. 9), ${ }^{16,37-40}$ whilst peaks at $c a$. 317,455 and $595 \mathrm{~cm}^{-1}$ can be attributed to contribution from acoustic phonons to the Raman scattering spectrum. ${ }^{41}$ The optical spectra (ESI, Fig. S4†) showed the expected excitonic transition features around $700 \mathrm{~nm} .^{42}$

When using similar amounts of $\left[\mathrm{MoCl}_{4}\left({ }^{n} \mathrm{Bu}_{2} \mathrm{~S}\right)_{2}\right]$ (ca. 30-70 mg) to that used in most of the $\mathrm{MoSe}_{2}$ depositions

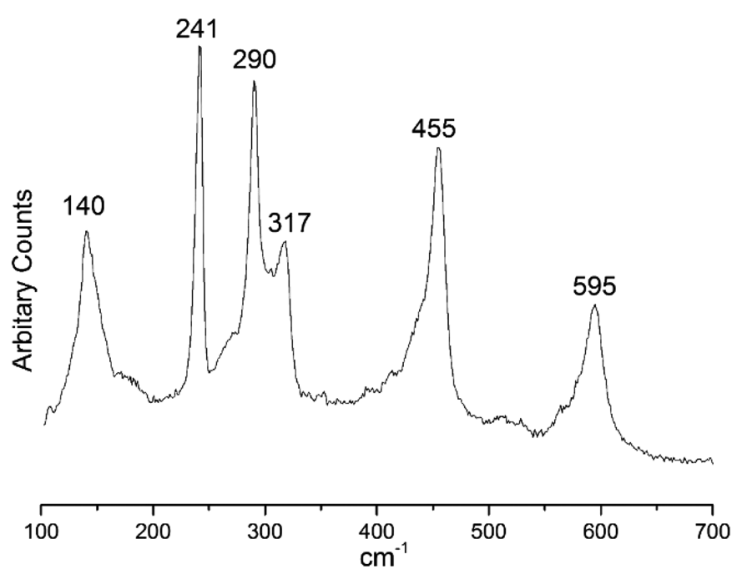

Fig. 9 Raman spectrum of the $\mathrm{MoSe}_{2}$ film deposited by LPCVD from $\left[\mathrm{MoCl}_{4}\left({ }^{n} \mathrm{Bu}_{2} \mathrm{Se}\right)_{2}\right]$ at $550{ }^{\circ} \mathrm{C}$.

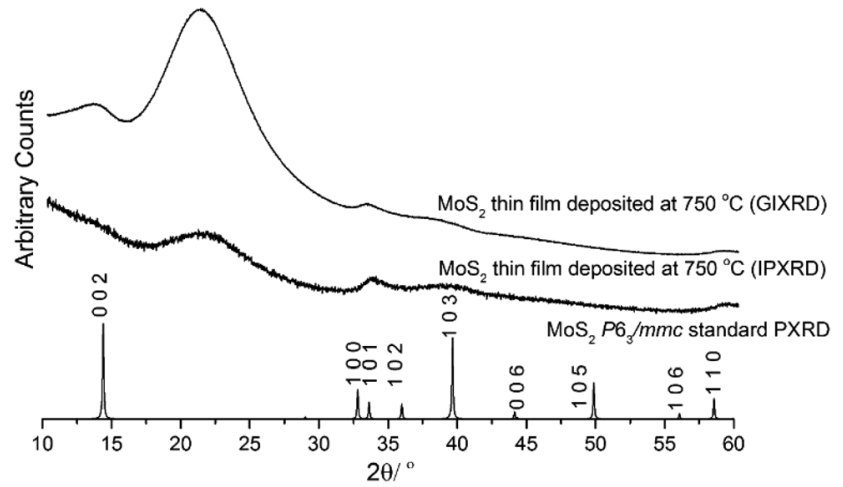

Fig. 10 Grazing incidence (incidence angle $=1^{\circ}$ ) and in-plane (incidence angle $=0.5^{\circ}$ ) XRD patterns from the $\mathrm{MoS}_{2}$ thin film deposited from $\left[\mathrm{MoCl}_{4}\left({ }^{n} \mathrm{Bu}_{2} \mathrm{~S}\right)_{2}\right]$ at $750{ }^{\circ} \mathrm{C}$, and the simulated XRD pattern from bulk $2 \mathrm{H}-\mathrm{MoS}_{2}{ }^{28}$ The broad feature at $2 \theta \sim 22^{\circ}$ is from the $\mathrm{SiO}_{2}$ substrate.

described above, CVD on $\mathrm{SiO}_{2}$ substrates at $750{ }^{\circ} \mathrm{C}$ resulted in very thin yellow films. These were too thin to generate any $\mathrm{X}$-ray diffraction in grazing incidence or in plane measurement, or to image effectively in the SEM, but did produce optical spectra consistent with $\mathrm{MoS}_{2}{ }^{42}$ (ESI, Fig. S5 $\dagger$ ). At lower temperatures no deposition occurred. However, by using larger amounts of $\left[\mathrm{MoCl}_{4}\left({ }^{n} \mathrm{Bu}_{2} \mathrm{~S}\right)_{2}\right](200 \mathrm{mg})$ at $750{ }^{\circ} \mathrm{C}$, silver films were obtained. Grazing incidence XRD (Fig. 10) showed similar features in these films to those seen for $\mathrm{MoSe}_{2}$ in Fig. 7, but with much weaker intensities. The pattern was dominated by the interlayer spacing peak (the 002 reflection), which gives no information on the exact phase of $\mathrm{MoS}_{2}$ produced. However, the in-plane XRD pattern contained stronger 100, 103 and 110 reflections, confirming that, like $\mathrm{MoSe}_{2}$, $\mathrm{MoS}_{2}$ adopted the $2 \mathrm{H}$ structure. The lattice parameters were refined as $a=3.13(5)$ and $c=13.7(8) \AA$, although there is significant uncertainty in this result due to the weak, broad peaks. Lattice parameters in ICSD are in the range $a=$ 3.14-3.16 $\AA$ and $c=12.29-12.53 \AA{ }^{28}$ The suppression of the 002 reflection in the in-plane pattern suggests $<00 l>$ preferred orientation like that observed in $\mathrm{MoSe}_{2}$, but unfortunately, the scattering from these films was not strong enough for pole figure measurements. The Raman spectrum recorded from the $\mathrm{MoS}_{2}$ film collected using $785 \mathrm{~nm}$ excitation showed weak bands at ca. 373 and $406 \mathrm{~cm}^{-1}$, assigned as the $\mathrm{E}_{2 \mathrm{~g}}$ and $\mathrm{A}_{1 \mathrm{~g}}$ vibrational modes in $2 \mathrm{H}-\mathrm{MoS}_{2} \cdot{ }^{37,40,41,43-45}$

SEM images confirm that the orthogonally oriented crystallites on the $\mathrm{MoS}_{2}$ film are very small, but that the underlying dense layer has a similar thickness to that found for $\mathrm{MoSe}_{2}$ ( 150 nm, Fig. 11). The weak and broad diffraction data suggest the crystallite sizes may also be smaller in the dense layer. Due to a close overlap between the $\mathrm{Mo}_{\alpha}(2.293 \mathrm{keV})$ and $S K_{\alpha}(2.307 \mathrm{keV})$ fluorescence peaks, it was not possible to obtain the Mo:S ratio from the EDX data. However, these did confirm the presence of both elements and there is no evidence for any residual $\mathrm{Cl}$ in the films. 

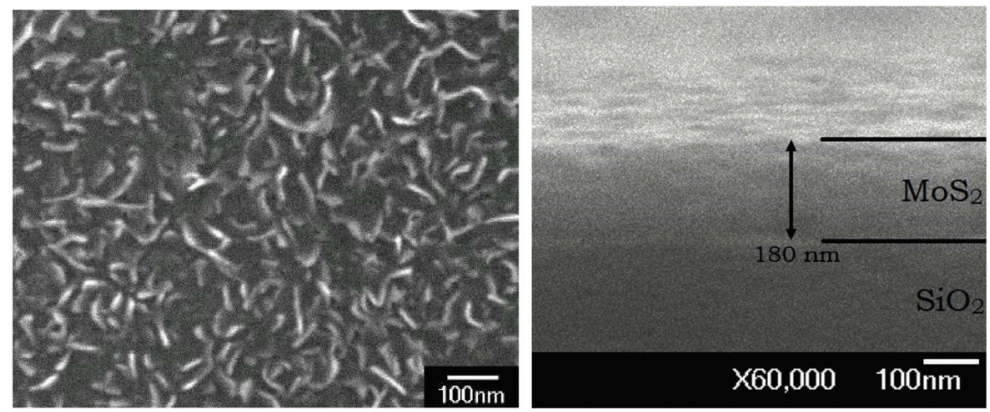

Fig. 11 SEM images of $\mathrm{MoS}_{2}$ films produced by CVD using $\sim 200 \mathrm{mg}\left[\mathrm{MoCl}_{4}\left({ }^{n} \mathrm{Bu}_{2} \mathrm{~S}\right)_{2}\right]$ at $750{ }^{\circ} \mathrm{C}$.

\section{Conclusions}

The synthesis and characterisation of a new series of welldefined, distorted octahedral Mo(Iv) chloride complexes with mono- and bi-dentate thioether and selenoether ligands has been demonstrated, with single crystal structures determined for several representative examples. TGA analysis of $\left[\mathrm{MoCl}_{4}\left({ }^{n} \mathrm{Bu}_{2} \mathrm{~S}\right)_{2}\right]$ and $\left[\mathrm{MoCl}_{4}\left({ }^{n} \mathrm{Bu}_{2} \mathrm{Se}\right)_{2}\right]$ suggested they may be sufficiently volatile to be used as sources of $\mathrm{MoS}_{2}$ and $\mathrm{MoSe}_{2}$, respectively. This was borne out by LPCVD experiments which produced silver $\left(2 \mathrm{H}-\mathrm{MoS}_{2}\right)$ and golden yellow $\left(2 \mathrm{H}-\mathrm{MoSe}_{2}\right)$ thin films. The identities of the films, crystallite sizes and morphologies were determined via XRD, SEM/EDX, Raman and optical measurements. The successful identification of single source CVD precursors for their deposition is an important development given the very high level of interest in thin films of these materials currently and their range of potential applications.

\section{Conflicts of interest}

There are no conflicts to declare.

\section{Acknowledgements}

We thank the EPSRC for support (through EP/K00509X/1, EP/ K009877/1 and EP/M508147/1) and the University of Southampton for a VC Scholarship (to Y.-P. C).

\section{References}

1 C. D. Garner and J. M. Charnock, in Comprehensive Coordination Chemistry, ed. G. Wilkinson, R. D. Gillard and J. A. McCleverty, Pergamon, Oxford, 1987, ch. 36.4; E. I. Stiefel, in Comprehensive Coordination Chemistry, ed. G. Wilkinson, R. D. Gillard and J. A. McCleverty, Pergamon, Oxford, 1987, ch. 36.5; G. J. Leigh and R. L. Richards, in Comprehensive Coordination Chemistry, ed. G. Wilkinson, R. D. Gillard and J. A. McCleverty, Pergamon, Oxford, 1987, ch. 36.2.
2 C. G. Young, in Comprehensive Coordination Chemistry II, ed. J. A. McCleverty and T. J. Meyer, Elsevier, Oxford, 2004, Vol. 4, Section 4.7.

3 E. I. Stiefel, Prog. Inorg. Chem., 1977, 22, 1.

4 M. Hidai and Y. Mizobe, in Metal Ions in Biological Systems, ed. A. Sigel and H. Sigel, Marcel Dekker, NY, 2002, vol. 39, p. 121.

5 Molybdenum and Tungsten; their role in biological processes, Metal ions in biological systems, ed. A. Sigel and H. Sigel, Marcel Dekker, NY, 2002, vol. 39.

6 M. Chhowalla, Z. Liu and H. Zhang, Chem. Soc. Rev., 2015, 44, 2584, (Eds. of themed issue on early transition metal dichalcogenides).

7 M. Chhowalla, H. S. Shin, G. Eda, L.-J. Li, K. P. Loh and H. Zhang, Nat. Chem., 2013, 5, 263; J. Liu and X.-W. Liu, Adv. Mater., 2012, 24, 4097.

8 J. R. Brent, N. Savjani and P. O’Brien, Prog. Mater. Sci., 2017, 89, 411.

9 Q. Xiang, J. Yu and M. Jaroniec, J. Am. Chem. Soc., 2012, 134, 6575; K. Lee, R. Gatensby, N. McEvoy, T. Hallam and G. S. Duesberg, Adv. Mater., 2013, 25, 6699; Z. Yan, C. Jiang, T. R. Pope, C. F. Tsang, J. L. Stickney, P. Goli, J. Renteria, T. T. Salguero and A. A. Balandin, J. Appl. Phys., 2013, 114, 20430.

10 J. S. Rhyee, J. Kwon, P. Dak, J. H. Kim, S. M. Kim, J. Park, Y. K. Hong, W. G. Song, I. Omkaram, M. A. Alam and S. Kim, Adv. Mater., 2016, 28, 2316; Y.-H. Chang, W. Zhang, Y. Zhu, Y. Han, J. Pu, J.-K. Chang, W.-T. Hsu, J.-K. Huang, C.-L. Hsu, M.-H. Chiu, T. Takenobu, H. Li, C.-I. Wu, W.-H. Chang, A. T. S. Wee and L.-J. Li, ACS Nano, 2014, 8, 8582; X. Wang, Y. Gong, G. Shi, W. L. Chow, K. Keyshar, G. Ye, R. Vajtai, J. Lou, Z. Liu, E. Ringe, B. K. Tay and P. M. Ajayan, ACS Nano, 2014, 8, 5125.

11 X. Lu, M. I. Utama, J. Lin, X. Gong, J. Zhang, Y. Zhao, S. T. Pantelides, J. Wang, Z. Dong, Z. Liu, W. Zhou and Q. Xiong, Nano Lett., 2014, 14, 2419; A. S. Pawbake, M. S. Pawar, S. R. Jadkar and D. J. Late, Nanoscale, 2016, 8, 3008.

12 J. Chen, X. Zhao, S. J. Tan, H. Xu, B. Wu, B. Liu, D. Fu, W. Fu, D. Geng, Y. Liu, W. Liu, W. Tang, L. Li, W. Zhou, T. C. Sum and K. P. Loh, J. Am. Chem. Soc., 2017, 139, 1073; Y. H. Lee, X. Q. Zhang, W. Zhang, M. T. Chang, C. T. Lin, 
K. D. Chang, Y. C. Yu, J. T. Wang, C. S. Chang, L. J. Li and T. W. Lin, Adv. Mater., 2012, 24, 2320.

13 K. K. Liu, W. Zhang, Y. H. Lee, Y. C. Lin, M. T. Chang, C. Y. Su, C. S. Chang, H. Li, Y. Shi, H. Zhang, C. S. Lai and L. J. Li, Nano Lett., 2012, 12, 1538; J. Pu, Y. Yomogida, K.-K. Liu, L.-J. Li, Y. Iwasa and T. Takenobu, Nano Lett., 2012, 12, 4013.

14 Y.-P. Chang, W. Levason and G. Reid, Dalton Trans., 2016, 45, 18393.

15 A. L. Hector, M. Jura, W. Levason, S. D. Reid and G. Reid, New J. Chem., 2009, 33, 64115; Y.-P. Chang, A. L. Hector, W. Levason and G. Reid, Dalton Trans., 2017, 46, 9824; S. L. Benjamin, C. H. de Groot, C. Gurnani, A. L. Hector, R. Huang, K. Ignatyev, W. Levason, S. J. Pearce, F. Thomas and G. Reid, Chem. Mater., 2013, 25, 4719; S. L. Benjamin, Y.-P. Chang, C. Gurnani, A. L. Hector, M. Huggon, W. Levason and G. Reid, Dalton Trans., 2014, 43, 16640; Y.-P. Chang, A. L. Hector, W. Levason and G. Reid, Dalton Trans., 2017, 46, 9824.

16 N. D. Boscher, C. J. Carmalt, R. G. Palgrave, J. J. Gil-Tomas and I. P. Parkin, Chem. Vap. Deposition, 2006, 12, 692.

17 J. Cheon, J. E. Gozum and G. S. Girolami, Chem. Mater., 1997, 9, 1847.

18 A. D. Westland and U. Uzelac, Can. J. Chem., 1970, 40, 2871; D. Sevdić and L. Fekete, Inorg. Chim. Acta, 1982, 57, 111; W. Levason, C. A. McAuliffe, F. P. McCullough, S. G. Murray and C. A. Rice, Inorg. Chim. Acta, 1977, 22, 227.

19 P. Dierkes, G. Frenzen, S. Wocadlo, S. Berger, J. Pebler and K. Dehnicke, Z. Naturforsch. Teil B, 1995, 50, 159.

20 L. Favero, F. Marchetti, G. Pampaloni and S. Zacchini, Dalton Trans., 2014, 43, 495.

21 F. R. Hartley, S. G. Murray, W. Levason, H. E. Soutter and C. A. McAuliffe, Inorg. Chim. Acta, 1979, 35, 265.

22 D. J. Gulliver, E. G. Hope, W. Levason, S. G. Murray, D. M. Potter and G. L. Marshall, J. Chem. Soc., Perkin Trans. 2, 1984, 429.

23 G. M. Sheldrick, Acta Crystallogr., Sect. C: Struct. Chem., 2015, 71, 3.

24 CrysAlis PRO, Agilent Technologies Ltd, Yarnton, Oxforshire, England.

25 CrystalClear-SM Expert 2.1 b29, Rigaku Corporation, Tokyo, Japan, 2012.

26 J. R. Dilworth and R. L. Richards, Inorg. Synth., 1990, 28, 33.
27 S. Grazulis, D. Chateigner, R. T. Downs, A. F. Yokochi, M. Quiros, L. Lutterotti, E. Manakova, J. Butkus, P. Moeck and A. Le Bail, J. Appl. Crystallogr., 2009, 42, 726.

28 ICSD: Inorganic Crystal Structure Database (ICSD), Fachinformationszentrum Karlsruhe (FIZ), accessed via the EPSRC funded National Chemical Database Service hosted by the Royal Society of Chemistry.

29 F. Stoffelbach, D. Saurenz and R. Poli, Eur. J. Inorg. Chem., 2001, 2699.

30 A. V. Butcher and J. Chatt, J. Chem. Soc. A, 1970, 2652.

31 A. Manteghetti, C. Belin, M. Tillard-Charbonnel, J.-L. Pascal, E. Clot and F. Favier, New J. Chem., 1999, 23, 165.

32 M. Bortoluzzi, E. Ferretti, M. Hayatifar, F. Marchetti, G. Pampaloni and S. Zacchini, Eur. J. Inorg. Chem., 2016, 3838.

33 B. Modec, J. V. Brenćić and L. Golic, Acta Crystallogr., Sect. C: Cryst. Struct. Commun., 2000, 56, 780.

34 B. N. Figgis and J. Lewis, Prog. Inorg. Chem., 1964, 6, 37.

35 A. B. P. Lever, Inorganic electronic spectroscopy, Elsevier, NY, 2nd edn, 1984.

36 Y.-P. Chang, W. Levason, M. E. Light and G. Reid, Dalton Trans., 2016, 45, 16262.

37 S. Sugai and T. Ueda, Phys. Rev. B: Condens. Matter Mater. Phys., 1982, 26, 6554.

38 A. Bachmatiuk, R. F. Abelin, H. T. Quang, B. Trzebicka, J. Eckert and M. H. Rummeli, Nanotechnology, 2014, 25, 365603.

39 Y.-H. Chang, W. Zhang, Y. Zhu, Y. Han, J. Pu, J.-K. Chang, W.-T. Hsu, J.-K. Huang, C.-L. Hsu, M.-H. Chiu, T. Takenobu, H. Li, C.-I. Wu, W.-H. Chang, A. T. S. Wee and L.-J. Li, ACS Nano, 2014, 8, 8582.

40 A. Roy, H. C. Movva, B. Satpati, K. Kim, R. Dey, A. Rai, T. Pramanik, S. Guchhait, E. Tutuc and S. K. Banerjee, ACS Appl. Mater. Interfaces, 2016, 8, 7396.

41 P. Soubelet, A. E. Bruchhausen, A. Fainstein, K. Nogajewski and C. Faugeras, Phys. Rev. B, 2016, 93, 155407.

42 N. Dong, Y. Li, Y. Feng, S. Zhang, X. Zhang, C. Chang, J. Fan, L. Zhang and J. Wang, Sci. Rep., 2015, 5, 14646.

43 K. K. Liu, W. Zhang, Y. H. Lee, Y. C. Lin, M. T. Chang, C. Y. Su, C. S. Chang, H. Li, Y. Shi, H. Zhang, C. S. Lai and L. J. Li, Nano Lett., 2012, 12, 1538.

44 Y. Shi, W. Zhou, A. Y. Lu, W. Fang, Y. H. Lee, A. L. Hsu, S. M. Kim, K. K. Kim, H. Y. Yang, L. J. Li, J. C. Idrobo and J. Kong, Nano Lett., 2012, 12, 2784.

45 W. Park, J. Baik, T. Y. Kim, K. Cho, W. K. Hong, H. J. Shin and T. Lee, ACS Nano, 2014, 8, 4691. 